\title{
Panorama del periodismo económico peruano en los medios impresos. Análisis de sus relaciones con los actores más relevantes
}

\section{Evelyn Coloma-Pinglo ${ }^{1}$ Tomás Ricardo Atarama-Rojas ${ }^{2}$}

Recibido: 2013-10-25

Enviado a pares: 2013-11-01
Aprobado por pares: 2013-12-18

Aceptado: 2014-01-18

DOI: 10.5294/pacla.2014.17.3.15

Para citar este artículo / To reference this article / Para citar este artigo

Coloma-Pinglo, E., Atarama-Rojas, T. R. Septiembre 2014. Panorama del periodismo económico peruano en los medios impresos. Análisis de sus relaciones con los actores más relevantes. Palabra Clave 17 (3), 920-945. D0I: 10.5294/pacla.2014.17.3.15

\section{Resumen}

En los últimos 25 años, la información económica ha venido ganando espacio en los medios de comunicación en el Perú. Hoy es un contenido estable en todos los diarios impresos de información general. No obstante, la formación de quienes trabajan en prensa económica no es suficiente, en la mayoría de los casos, para profundizar en los temas e incentivar el análisis. Entender el movimiento de los actores que condicionan esta especialidad periodística es, pues, el mayor reto para llevar la información especializada al público general y responder a su derecho a la información.

\section{Palabras clave}

Periodismo económico, periodismo en el Perú, prensa económica (Fuente: Tesauro de la Unesco).

\footnotetext{
Universidad de Piura, Perú. ev.coloma@gmail.com

Universidad de Piura, Perú. tomas.atarama@udep.pe
} 


\section{Overview of Economic Journalism in Peruvian Print Media. Analysis of Its Association with the Most Relevant Players Relationship}

\section{Abstract}

Economic, business and financial news has gained ground in the media in Peru during the past 25 years. Today, these articles are part of every general-interest daily newspaper. However, the educational level of most people employed in the economic press industry is insufficient to write about economics in depth or to promote analysis. Therefore, understanding how the actors who condition business journalism operate is the biggest challenge to making this type of specialized information available to the general public and to responding to the public's right to information.

\section{Keywords}

Business journalism, journalism in Peru, economic press, Peruvian journalists (Source: UNESCO Thesaurus). 


\section{Panorama do jornalismo econômico peruano nos meios impressos. Análise de suas relações com os atores mais relevantes}

\section{Resumo}

Nos últimos 25 anos, a informação econômica vem ganhando espaço nos meios de comunicação no Peru. Hoje é um conteúdo estável em todos os jornais impressos de informação geral. Contudo, a formação dos que trabalham na imprensa econômica não é suficiente, na maioria dos casos, para aprofundar nos temas e incentivar a análise. Entender o movimento dos atores que condicionam essa especialidade jornalística é o maior desafio para levar a informação especializada ao público geral e responder a seu direito à informação.

\section{Palavras-chave}

Jornalismo econômico, jornalismo no Peru, imprensa econômica (Fonte: Tesauro da Unesco). 


\section{Introducción}

La de periodismo y economía puede parecer una combinación difícil, forzada o insulsa. Por un lado, la economía es una de las ciencias sociales con más altos niveles de complejidad formal, apoyada en las ciencias exactas, $y$, por el otro, los periodistas se han caracterizado tradicionalmente por un desapego a los números y un interés en las historias que impactan al público masivo.

Sin embargo, la proliferación de los medios especializados en información económica en todo el mundo, así como la inclusión de secciones de economía dentro de las publicaciones de información general, es evidente desde hace más de una década, como una consecuencia natural del interés de los ciudadanos por estas noticias (Calvo, 2011).

De hecho, la comunicación en torno a la actualidad económica no es un fenómeno reciente, sino que se remonta a los textos clásicos del periodismo de los siglos XV y XVI, ${ }^{3}$ controlados por la casa comercial alemana de los Függer y por el agente comercial inglés Thomas Greshman (Del Río, 2004). Luego, con la imprenta, las listas marítimas y listas de precios o price-currents pasaron a ser parte esencial del negocio de la burguesía mercantil, convirtiéndose en los primeros periódicos financieros y comerciales.

Así, desde sus orígenes el avance de esta prensa especializada ha ido de la mano con los movimientos de los actores que marcan la vida económica de la sociedad. ${ }^{4}$ Por eso, con el fortalecimiento del capitalismo financiero e industrial y la profesionalización del periodismo y de la economía como disciplinas, las principales economías occidentales vieron a partir de la segunda mitad del siglo XIX el surgimiento de las grandes publicaciones

3 Incluso, algunos autores consideran que la difusión de información económica es anterior a la aparición del periodismo. Álvarez (1985, citado en Esteve y Fernández, 1999) señala que las primeras noticias económicas se pueden encontrar en las crónicas que el ciudadano romano M. Celius Rufus enviaba a Cicerón cuando éste era cónsul de Cicilia, ya que narraba los movimientos de los negocios de la época.

4 Real (2007, p. 184) pone énfasis en que un periodista económico es, ante todo, un periodista: "Conviene aclarar que sólo cabe hablar de un único Periodismo y de un solo periodista. Que las divisiones que hacen mención a periodismos o periodistas diferentes en función del medio de comunicación social o el tipo de información que elaboran, conducen a una confusión conceptual que debe ser evitada (...). Las variantes laborales que conllevan los distintos medios y temáticas informativas, no modifican la esencia del periodismo ni del periodista". 
financieras anglosajonas, algunas de las cuales circulan hasta hoy. La revista The Economist nació en 1843 como un vehículo de difusión de la doctrina de Adam Smith, y unas décadas más tarde le siguieron los primeros diarios financieros estables, como Financial News (1884), Financial Times (1888) $y$ Wall Street Journal (1882).

Por su parte, la información económica en el Perú tendría que esperar hasta la década de 1990 -que supuso unas reformas de mercado y el reingreso del país a los circuitos internacionales- para hacerse con un espacio en los principales medios nacionales y motivar la fundación de algunos títulos especializados. En cambio, en los países desarrollados se puede hablar de una popularización de la prensa económica y de su extensión a la radio y la televisión desde los años setenta (Arrese, 2000a).

En este trabajo se pretende analizar esta y otras peculiaridades de la cobertura de los hechos económicos en el Perú, tomando como referencia la prensa económica mundial. Para esto, se hará un análisis de los actores sociales que condicionan esta área de especialización periodística en el país y se apuntarán los retos que deberán asumir los profesionales de esta área.

\section{Periodismo económico: una especialización delicada}

El periodismo económico - tal como afirma Arrese (2004) - queda definido por el tipo de temas que cubre. ${ }^{5}$ De ahí que la información económica, financiera o empresarial de actualidad tenga especifidades que se derivan de su propia naturaleza.

Por un lado, quienes consumen las notas de actualidad económica suelen estar relacionados directamente con la vida económica de la sociedad. Se trata de un público educado, generalmente con poder económico o político. Y, por esto, se muestra especialmente interesado en esta cobertura. Endo (2006, p. 47) cita las declaraciones de Dan Bogler, uno de los edito-

5 "La economía es el objeto sobre el que se informa, entendiendo por esta toda actividad humana destinada a la satisfacción de unas necesidades mediante unos recursos escasos” (Vara, 2004, p. 102). 
res del Financial Times, acerca de este tipo de audiencia más activa para obtener la información que los consumidores de otros medios: "Me encanta el Financial Times, pero no es un diario que se lea por diversión. Es difícil de leer. Es técnico, detallado, pesado. Uno no encuentra notas sobre farándula o la televisión. Usualmente, la persona lo lee porque tiene que hacerlo, porque afecta los negocios en su vida”.

No obstante, los temas económicos, financieros y empresariales también llegan al gran público a través de los medios de información general que dedican un espacio a la economía. Tras muchas décadas de vivir a la sombra de otras especializaciones más populares, como la política o la deportiva, la información económica ha dejado de ser un terreno reservado a expertos hasta convertirse en un área de interés, aún minoritario, pero cada vez más extendido entre los ciudadanos (Arrese y Media, 2002b).

De esta manera, el público general, aunque no constituye la audiencia tradicional del periodismo económico, también consume la información especializada, ya que impacta su vida cotidiana. ${ }^{6}$ En este caso, se podría hablar de una subespecialización de la prensa económica, con un mayor énfasis en la simplificación y claridad (Millman, 2006 y Saporito, 1999).

Por otro lado, quienes ejercen o han analizado la prensa económica coinciden en que la elaboración del producto informativo está sujeta a especiales exigencias de rigor, por su alta sensibilidad y los efectos inmediatos que puede tener en los mercados. Del Río (2004, p. 29) detalla:

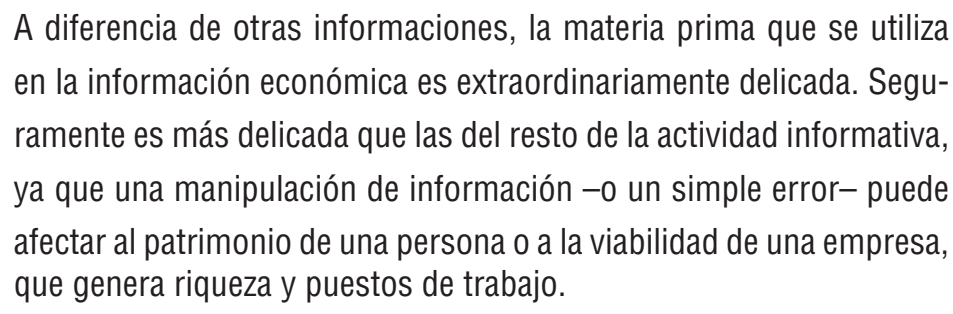

6 Galindo (2008, p. 152) explica por qué algunos tienen la percepción equivocada de que la información económica poco tiene que ver con la vida de los ciudadanos: "Esto, por cuanto los hechos económicos no siempre se manifiestan directamente, sino que es necesario un trabajo adicional de lectura de la realidad, alguna mediación operativa. El déficit fiscal no es algo que esté en la casa de los lectores. Muchos de los hechos económicos son abstracciones de la realidad, y por lo tanto se nombran con un lenguaje igualmente abstracto, alejado de la sensibilidad cotidiana”. 
Esta delicadeza es, pues, una consecuencia de la complejidad inherente a la ciencia económica. De hecho, la complejidad es considerada la primera gran barrera que dificulta la cobertura periodística de la economía. Sobre todo, si se toma en cuenta que los ejecutivos o funcionarios están mejor educados en el mundo empresarial que la mayoría de los periodistas dedicados a cubrirlo, generando una asimetría que pone a los reporteros en desventaja y que podría tener un impacto negativo en la calidad de producto informativo.

Con todo, los profesionales del área tienen como meta encontrar una posición entre el conocimiento pleno y la ignorancia absoluta sobre finanzas, contabilidad o mercados de capital, que les permita entender los hechos económicos relevantes para informar a la audiencia con veracidad y rigor (Lewin, 2002).

Además, tal rigor debe estar alineado a promover el atractivo del discurso periodístico. Generalmente, se asocia a las secciones de economía con una materia aburrida o poco interesante, frente a otros contenidos de los medios de comunicación. Y esta imagen negativa tiene que ver con el uso de un lenguaje especializado, lejano para el público.

Si bien se ha desarrollado un proceso de popularización del lenguaje económico que lo vuelve perceptible al gran público, todavía persisten en la práctica ciertos tecnicismos. Como comentan Coca y Díezhandino (1997, p. 59), "el lenguaje críptico, oscurantista a golpe de tanto gusto por el neologismo fácil, es muy propio de la información económica. Llena de tecnicismos, de préstamos de otros campos con los que se intenta celosa pero muy a menudo equivocadamente informar con el rigor, el tono y el nivel del experto".

Otra de las peculiaridades de esta especialización periodística es la de acercar los hechos al lector para revelar las consecuencias en su vida cotidiana. Ya que, para explicar el comportamiento económico de un país, es necesario agrupar los datos en variables intangibles y no visibles directamente, con el fin de ofrecer una visión simplificada pero operativa que permita a los principales agentes económicos tomar decisiones (Vara, 2004). 
La tasa de desempleo, el producto interno bruto interno (PIB) y el índice de bancarización son algunos ejemplos de esta abstracción que, como realidades cuantitativas, sintetizan las decisiones económicas de millones de ciudadanos y requieren de una traducción. ${ }^{7}$

Por último, ${ }^{8}$ las peculiaridades de la prensa económica también se delimitan en la búsqueda de la información; esto es, en la relación con las fuentes. Por esta razón, el análisis del panorama nacional incluirá, en un apartado independiente, una mirada a los actores que intervienen en el ámbito peruano.

\section{Análisis de la prensa económica peruana}

Los primeros años de la década de los noventa representaron un giro en casi todos los ámbitos de la economía del Perú y cambiaron la forma de hacer periodismo económico en el país. Incluso, se podría decir que la verdadera especialización en economía peruana nació en esta época.

Para David Rivera (2013), director de la revista Poder, la prensa económica peruana era incipiente aun en los años noventa y recién vive un despegue a partir del 2000:

Si uno compara los resultados económicos, ve que la situación mejora con democracia. Es muy importante la estabilidad, que empieza con el gobierno de Alejandro Toledo en el 2001. Aquí despega la inversión privada con fuerza y también el periodismo económico. En esta época, El Comercio ya tenía a Gestión, aparece Poder y Semana Económica se renueva. También salen los programas económicos en la televisión. ${ }^{9}$

7 Arrese (2004, p. 298) apunta al respecto: "Ese carácter abstracto e impersonal de la actualidad económica puede dar la errónea impresión de que la Economía, como sistema, se impone necesariamente y funciona de forma mecánica al margen de la actuación de las personas -incluso al margen de sus problemas-, y de forma autónoma respecto a otros ámbitos como el social o el político. Actores y sujetos verbales tan ilocalizables como 'la economía, 'los mercados', 'la coyuntura internacional', 'la industria', etc. parecen ser los responsables de nuestro bienestar (...). El antídoto contra la abstracción es la personalización, o mejor, la adjudicación de causas y efectos a protagonistas individuales o colectivos, identificados con claridad”.

8 Aparte de lo ya mencionado, Esteve y Fernández (1999) incluyen entre las características propias de los contenidos de información económica un mayor espacio para el análisis y el comentario en comparación con otras áreas especializadas. Asimismo, señalan que en las secciones de economía suelen utilizarse con mayor frecuencia los gráficos, infografías y cuadros estadísticos.

9 Rivera del Águila, David (23 de octubre de 2013). Comunicación personal. 
Antes de 1990, se puede registrar como primer título económico la revista Perú Económico, que nació en 1978, fundada por Felipe Ortiz de Zevallos, como un boletín mensual de análisis profundo de la actualidad macroeconómica nacional, que en ese entonces atravesaba una crisis generalizada. ${ }^{10}$ Unos años después, en junio de 1982 , salió al mercado $1 / 2$ de Cambio, bajo la dirección de Guido Pennano Allison, también con un enfoque macro en los indicadores económicos, aunque incluyó los movimientos de la bolsa, la minería y otros negocios que en ese momento ofrecían nuevas oportunidades de trabajo.

\section{Y en 1985 nació Semana Bursátil como una publicación del Grupo} Apoyo, especializada en los movimientos de la Bolsa de Valores de Lima (BVL), porque en ese tiempo la plaza limeña incrementó sus movimientos, generando un mayor interés. ${ }^{11}$

Así, la prensa económica peruana llegó hasta la década de los noventa sin una tradición de publicaciones diarias. Poco después del cambio de gobierno de 1990, Manuel Romero Caro lanzó al mercado el diario Gestión en el mes de septiembre, pues previó que la nueva coyuntura ${ }^{12}$ generaría una demanda por información especializada en economía. De igual forma, apareció el diario Síntesis en 1991, aunque desapareció rápidamente, pues la demanda por información económica no era suficiente para mantener a dos diarios especializados en el mercado. ${ }^{13}$

10 El PIB peruano se contrajo en términos reales cuatro veces durante la década de los ochenta. El déficit fiscal de dos dígitos (como porcentaje del PIB) y las brechas en la cuenta corriente de su balanza de pagos, en torno al 10\% del PIB, fueron los principales síntomas de una política económica insostenible. La aceleración de la inflación fue otro signo de la mala gestión económica: se alcanzaron estándares de hiperinflación (tasas anuales de cuatro dígitos) en 1988, 1989 y 1990.

11 De acuerdo con David Rivera (2013), en 1987, con la ley de la estatización de la banca, Semana Bursátil se convirtió en Semana Económica para incluir temas económicos de coyuntura. Así se formó la revista que circula hasta hoy. En el 2007 la edición impresa adoptó uno de los mayores cambios en su diseño. Según información de la empresa, en 1995 ésta se constituyó como filial de Grupo Apoyo con el nombre de Apoyo Comunicaciones y, desde el 2002, tras la separación de la división de proyectos de comunicación estratégica, hasta julio de 2012, funcionó como Apoyo Publicaciones. Hoy la empresa opera con absoluta autonomía respecto de las empresas filiales de Apoyo.

12 Un drástico plan de estabilización conocido como Fuji-Shock y reformas de mercado en casi toda la economía, ejecutados durante los primeros años de la década de los noventa, mejoraron el desempeño económico del Perú en los siguientes años. No obstante, la economía peruana continuó experimentado tasas de crecimiento negativas en algunos de esos años. La recesión de 1990 podría atribuirse a las medidas ineludibles de ajuste que se necesitaban para abatir la hiperinflación heredada de los años ochenta (Yamada y Castro, 2010).

13 El diario Gestión permaneció en el mercado y sigue en circulación hasta el día de hoy, como parte del grupo El Comercio, desde la venta de la publicación en el 2007. 
Por su parte, El Comercio incluyó desde junio de 1994 una sección estable e independiente de economía en el cuerpo $\mathrm{E}$ de su edición diaria. También, surgió en el mismo año la revista Business, Negocios en el Perú, para informar sobre economía y las oportunidades para crear empresas en el país. No obstante, la primera revista exclusivamente de negocios nació recién en el 2008 con la edición peruana de América Economía.

Ya en la década del 2000, El Comercio lanzó el suplemento Día 1 en el 2004; Poder publicó su edición nacional desde marzo de 2009; el diario Gestión creó su propia revista de negocios, $G$ de Gestión, en diciembre de 2010, y en febrero de 2012 El Comercio apostó por la información económica los domingos con el suplemento Portafolio Económico.

Además de estas publicaciones, orientadas principalmente a temas económicos, financieros y de negocios, la presencia de la economía en el Perú ha calado hasta los medios de información general nacionales y en los principales títulos locales.

En el siguiente cuadro se muestra el espacio que dedica actualmente cada diario generalista peruano a las secciones de economía. Para elaborarlo, se examinaron todas las ediciones de las publicaciones con alcance nacional durante tres semanas. ${ }^{14}$ Del análisis realizado, se puede afirmar que en el $85 \%$ de los casos las noticias económicas se publican todos los días y ocupan una sección fija dentro del diario, con un número de páginas establecido por día. Esto supone que, de manera similar a las principales economías occidentales, una parte de los periodistas económicos en el Perú se dirige al público general, que no se encuentra especialmente interesado en la economía y demanda una traducción clara del impacto que tienen los acontecimientos económicos del país en sus vidas.

Según Ricardo Montero (2013), jefe de informaciones de Gestión, además de estas secciones especializadas, cada vez son más los periódicos generalistas, como El Comercio o Perú21, que suelen analizar la actualidad

14 Se monitorearon los diarios nacionales del 30 de septiembre al 20 de octubre de 2013. 


\section{Cuadro 1 \\ Secciones económicas en medios impresos de información general}

\begin{tabular}{|c|c|c|c|c|}
\hline Periódico & Nombre de sección & Número de páginas & Frecuencia & Páginas del medio \\
\hline Correo & Política y Economía & $\begin{array}{l}\text { Lunes a sábado: } 5 \\
\text { Domingo: de } 7 \text { a } 8 \text { a }\end{array}$ & Diaria & $\begin{array}{c}\text { Lunes a sábado: } 24 \\
\text { Domingo: } 32\end{array}$ \\
\hline Diario16 & Economía & 1 & Esporádica & 16 \\
\hline El Comercio & $\begin{array}{c}\text { Lunes: Día } 1 \\
\text { Martes a sábado: Economíab } \\
\text { Domingo: Portafolio Económico }\end{array}$ & $\begin{array}{c}\text { Lunes: } 32 \mathrm{c} \\
\text { Martes a Viernes: } 16 \mathrm{~d} \\
\text { Sábado: } 20 \\
\text { Domingo: } 20\end{array}$ & Diaria & $\begin{array}{c}\text { Lunes:e } 86 \\
\text { Martes: } 66 \\
\text { Miércoles: } 60 \\
\text { Jueves: } 84 \\
\text { Viernes: } 72 \\
\text { Sábado: } 92 \\
\text { Domingo:84 }\end{array}$ \\
\hline Expreso & Economía & 2 & Diaria & 24 \\
\hline La Primera & $\begin{array}{l}\text { Lunes a sábado: Economía } \\
\text { Domingo: Negocios }\end{array}$ & 2 & Diaria & $\begin{array}{c}\text { Lunes a sábado: de } 24 \text { a } 32 \\
\text { Domingo: } 40\end{array}$ \\
\hline La República & Economía & $\begin{array}{c}\text { Lunes a sábado: } 3 \mathrm{f} \\
\text { Domingo: } 4\end{array}$ & Diaria & $\begin{array}{c}\text { Lunes a sábado: } 32 \\
\text { Domingo: } 40\end{array}$ \\
\hline Perú21 & Economía & $\begin{array}{c}\text { Lunes a sábado: } 3 \\
\text { Domingo: } 2 \mathrm{~g}\end{array}$ & Diaria & 28 \\
\hline
\end{tabular}
(a) Incluye página Empresas y Negocios.
(b) Incluye dentro de la sección las páginas de Clasificados.
(c) Puede aumentar hasta 56 páginas, por suplementos especiales.
(d) En miércoles aumenta según publicidad.
(e) Todos los días varía según la publicidad. No incluye suplementos de fin de semana.
(f) Lunes publica página Soy empresa.
(g) Incluye página Historia de éxito.

nacional desde un enfoque económico, de manera que noticias de la sección política o de locales incluyen información relacionada con la economía nacional. ${ }^{15}$

De hecho, en la prensa peruana ya existe la intención de llegar con información económica a un público más amplio que el nicho experto, interesado en el área desde sus inicios en el Perú. David Rivera (2013), quien fue uno de los gestores del suplemento Día 1, explica los objetivos que tuvo el proyecto:

Para el 2004 la economía era interesante para muchas más personas de lo que creían los medios. Por eso, le propongo a El Comercio crear un producto más abierto. Día 1 surge tratando temas duros de

15 Montero Reyes, Ricardo (20 de octubre de 2013). Comunicación personal. 
economía, pero también incluye informes sobre centros comerciales u otras notas que le puedan interesar a todo el mundo. Y parte del reto era escribir de forma sencilla, acompañar las notas con gráficos 0 infografías que simplifiquen los temas y los vuelvan más ligeros. ${ }^{16}$

\section{Formación de los periodistas económicos en Perú}

Ahora, antes de estudiar el acercamiento de los periodistas peruanos a los actores de la vida económica nacional, es preciso detenerse a analizar el grado de formación de los reporteros económicos. A nivel internacional, el debate sobre la adecuada formación de los profesionales que se dedican a la información económica permanece hasta hoy. ${ }^{17}$ ¿Es mejor una redacción económica formada básicamente por periodistas o conviene incluir más economistas en el grupo de reporteros? ¿Los periodistas deben estudiar una especialización en economía o los economistas pueden comunicar?

En este aspecto, lo razonable es que el profesional entienda el papel y el discurso de los actores que mueven la economía de la sociedad para que la producción periodística satisfaga el derecho a la información de la audiencia. El objetivo para el periodista económico, se entiende, no es convertirse en un contador, un analista financiero o administrador de fondos, sino tener los conocimientos suficientes para entender el mundo económico que busca cubrir (Watts, 2006).

Vara y Arrese (2003, p. 496) anotan:

Es cierto que la formación propia de la tarea periodística, que da sentido a la profesionalidad de los informadores, tiene un lugar de primus inter pares respecto a otros requisitos formativos, pero también lo es que esa tarea nunca se puede cumplir satisfactoriamente en ámbitos periodísticos especializados sin los complementos de formación específica que correspondan en cada caso.

16 Rivera del Águila, David (23 de octubre de 2013). Comunicación personal.

17 "Hoy, como en el pasado, se sigue reflexionando sobre el tipo de formación más adecuada para el periodista económico. Un profesional que continúa siendo objeto de críticas, desde muy distintas ópticas: por su supuesta incapacidad para profundizar en asuntos complejos, por su desconocimiento de cuestiones básicas en torno al funcionamiento de la actividad económica, por la dificultad que encuentra para traducir la actualidad, con rigor, a un lenguaje comprensible; y por su indefensión ante la actuación de fuentes, especialistas y defensores de intereses particulares" (Vara y Arrese, 2003, p. 493). 
En la prensa económica peruana de información general, de acuerdo a un sondeo realizado para este artículo, ${ }^{18}$ el $90 \%$ de los profesionales que trabajan en las secciones de economía de los medios de información general estudió la carrera de periodismo o comunicación en la universidad, mientras que el $10 \%$ se graduó como economista. En concreto, como muestra el siguiente cuadro, sólo el diario El Comercio incluye a tres economistas en el grupo de su sección económica. ${ }^{19}$

\section{Cuadro 2 \\ Profesionales en medios impresos de información general*}

\begin{tabular}{|c|c|c|c|c|c|}
\hline Medio & Cargos & $\begin{array}{c}\text { N. o de } \\
\text { economistas }\end{array}$ & N. o de periodistas & Otros & Total \\
\hline Correo & $\begin{array}{c}1 \text { editor } \\
1 \text { redactor }\end{array}$ & 0 & 2 & - & 2 \\
\hline Ex Comercio & $\begin{array}{c}1 \text { editor general } \\
4 \text { jefes } \\
12 \text { redactores }\end{array}$ & 3 & 14 & 1 abogado & 17 \\
\hline La Primera & $\begin{array}{c}1 \text { colaborador de otra } \\
\text { sección }\end{array}$ & 0 & 1 & - & 0 \\
\hline La República & $\begin{array}{c}1 \text { editor } \\
1 \text { redactor }\end{array}$ & 0 & 2 & - & 2 \\
\hline Peditor 21 & $\begin{array}{c}1 \text { editor } \\
4 \text { redactores }\end{array}$ & 0 & 5 & - & 5 \\
\hline
\end{tabular}

${ }^{*}$ No incluye a practicantes.

Los resultados indican que los medios de información general peruanos apuestan por la capacidad de los periodistas para interpretar el desarrollo económico del país e interactuar con los actores que marcan la pauta en la materia. Asimismo, se puede ver, como consecuencia de este panorama, una confianza cada vez más extendida en presentar historias económicas, sobre todo las que involucran a empresarios emprendedores, en forma de crónicas o reportajes.

18 Se encuestó a 15 periodistas económicos peruanos en octubre del 2013, trabajadores de diferentes periódicos, sobre la formación de los profesionales que constituyen las secciones económicas de sus medios.

19 El Departamento de Economía \& Negocios de El Comercio se encarga de la edición diaria de la sección Economía, los suplementos Día 1, Portafolio Económico y la edición web de la sección económica. 
La investigación también señala que, aunque ninguno de los periodistas de la prensa económica peruana tiene una maestría en economía o finanzas, el $82 \%$ de estos profesionales ha recibido al menos un curso o diplomado de corta duración relacionado con la especialización. La mayoría de estas capacitaciones, cabe señalar, fueron dictadas por empresas privadas o entidades gubernamentales, que suelen ser fuentes tradicionales, como la Bolsa de Lima (BVL), el Banco Central de Reserva (BCR), la Superintendencia de Banca, Seguros y AFP (SBS), entre otras, además de las universidades o institutos.

Entre la prensa escrita económica del Perú, resulta valioso mencionar el caso de Gestión, ya que es el único periódico especializado en economía de tiraje diario. Este medio, que nació en 1991 con una redacción conformada principalmente por economistas, hoy cuenta con periodistas en todas sus secciones, excepto en la de Finanzas. ${ }^{20} \mathrm{Y}$, aunque los editores no son periodistas, se impulsa la publicación de crónicas y entrevistas narradas.

Para ahondar sobre este punto, se ha analizado la oferta de las universidades peruanas en la formación del periodista económico. Se han tenido en cuenta los planes de estudio de 19 facultades o escuelas de comunicación en el Perú entre las 35 mejores universidades del país de 2012, según el ranking de la revista América Economía. ${ }^{21}$ Esta muestra supone el 50\% del total de los centros que forman periodistas. ${ }^{22}$

El estudio, aunque parcial, revela que sólo la Escuela de Ciencias de la Comunicación de la Universidad Nacional Federico Villarreal y la Facultad de Comunicación de la Universidad de Lima incluyen un curso obligatorio de periodismo económico. Por tanto, para este análisis también se consideraron las asignaturas que forman tangencialmente al especialista en

20 Entre las secciones Economía, Negocios, Finanzas, Internacional e Investigación de la edición impresa del diario, Gestión cuenta con cinco editores y trece redactores. De estos dieciocho profesionales, ocho son periodistas, ocho son economistas, uno es administrador de empresas y otro, abogado.

21 De las primeras 35 universidades del ranking de América Economía de 2012, sólo 22 cuentan con la carrera de comunicación. En el estudio, se consultó la información disponible en las páginas web de cada universidad durante la semana del 5 al 12 de diciembre de 2013.

22 Según la Asamblea Nacional de Rectores, en el Perú operan 38 facultades de comunicación o escuelas dependientes de facultades de educación y humanidades o de ciencias sociales. 
información económica, como el curso de economía. El siguiente cuadro muestra los resultados de la investigación.

\section{Cuadro 3 \\ Formación en economía para periodistas en universidades peruanas*}

\begin{tabular}{|c|c|}
\hline Universidad & Nombre de asignaturas \\
\hline Pontificia Universidad Católica del Perú & $\begin{array}{c}\text { Economía } \\
\text { Finanzas para Comunicadores (electivo) }\end{array}$ \\
\hline Universidad Nacional Mayor de San Marcos & - \\
\hline Universidad de Lima & $\begin{array}{c}\text { Economía General } \\
\text { Periodismo Político y Económico }\end{array}$ \\
\hline Universidad de Piura & Economía \\
\hline Universidad Nacional de San Antonio Abad del Cusco & - \\
\hline Universidad San Martín de Porres & $\begin{array}{c}\text { Economía } \\
\text { Política y Economía Internacional }\end{array}$ \\
\hline Universidad Nacional Federico Villarreal & $\begin{array}{c}\text { Economía Política } \\
\text { Periodismo Económico }\end{array}$ \\
\hline Universidad Nacional San Agustín de Arequipa & - \\
\hline Universidad Peruana de Ciencias Aplicadas & Economía para la Gestión \\
\hline Universidad Nacional de Trujillo & $\begin{array}{c}\text { Historia de las Ideas Económicas } \\
\text { Desarrollo Socioeconómico del Perú }\end{array}$ \\
\hline Universidad San Ignacio de Loyola & Economía General \\
\hline Universidad Nacional Jorge Basadre Grohmann de Tacna & Economía de la Comunicación \\
\hline Universidad Nacional de Piura & $\begin{array}{c}\text { Fundamentos de Economía } \\
\text { Tendencias Económicas Contemporáneas }\end{array}$ \\
\hline Universidad Católica de Santa María & - \\
\hline Universidad Tecnológica del Perú & - \\
\hline Universidad Privada Antenor Orrego & Economía General \\
\hline Universidad Inca Garcilaso de la Vega & Economía \\
\hline Universidad César Vallejo & - \\
\hline Universidad Nacional del Centro del Perú & Economía y Desarrollo Regional \\
\hline
\end{tabular}

*Estas universidades se ubican dentro de las 35 mejores del país en 2012, según América Economía.

Del estudio se desprende que el 31,5\% de las facultades que forman periodistas no incluye ningún curso en su plan de estudios relacionado con información económica, lo que evidencia la falta de formación antes mencionada entre los profesionales de la prensa económica peruana.

En tanto, la oferta de los posgrados en el ámbito nacional también es escasa o casi nula, pues no hay programas fijos de maestrías en periodismo 
económico. Diplomados especializados, como el de la Universidad Católica San Pablo en Arequipa, ${ }^{23}$ forman parte de la excepción y no de la regla.

En resumen, si bien se puede afirmar que existe el interés por una formación continua, en el Perú son pocos los periodistas con una formación suficiente para desenvolverse con soltura en la especialización. Existe un vacío en los conocimientos que les permitirían profundizar en los temas e ir más allá de lo dictado por las fuentes.

La formación supone, así, un reto para los periodistas económicos peruanos. Con el fin de no afectar la calidad de las publicaciones, los profesionales tendrán que buscar la educación especializada de forma independiente o de la mano de sus empleadores y complementar la formación que recibieron en las escuelas de periodismo. Dentro o fuera del Perú, lo ideal sería estudiar programas dirigidos a licenciados y profesionales, como los másters y cursos superiores o los seminarios, workshops, etc., de duración corta. ${ }^{24}$

\section{Actores que condicionan el quehacer periodístico}

El mundo de la economía abarca diferentes temas, cuya cobertura ha creado verdaderas subespecialidades dentro del periodismo económico. Sin embargo, con ánimo expositivo, aquí se tomarán en cuenta tres bloques temáticos que se ajustan a la realidad del Perú -que tradicionalmente se identifican con las secciones básicas de un medio especializado en economía-: la macroeconomía, la microeconomía y el sistema financiero.

Aquí se detallará lo que informa cada subsección y las fuentes ${ }^{25}$ de donde se obtiene la información en el Perú, porque éstas constituyen los actores sociales con los que interactúa el periodista. Del tratamiento de la

23 Si bien la Universidad Católica San Pablo de Arequipa no cuenta con una Facultad de Comunicación, ofrece un diplomado en Periodismo Económico y Minería, debido a la importancia de la actividad minera en esa región del Perú.

24 Vara y Arrese (2003) esperan que, en línea con el casi imparable ascenso de los contenidos económicos en los medios, las universidades, y en concreto las facultades de comunicación, refuercen su apuesta por el perfil de los periodistas económicos e incluyan en su plan de estudios más materias ligadas a esta especialización periodística.

25 Sin hacer un análisis exhaustivo de la tipología de las fuentes que abarca el periodismo económico, es preciso anotar la clasificación que establece Arrese (2004): privadas, institucionales, documentales, periodísticas y expertas. 
información expuesto previamente se desprende que estas fuentes son interesadas, con poder y una gran sensibilidad.

En cada bloque temático, la prensa económica recurre a cuatro categorías de fuentes: las oficiales, que provienen de las instituciones gubernamentales; las privadas, de empresas y gremios empresariales; las documentales, que incluyen los reportes de empresas consultoras, centros de investigación, agencias calificadoras y agentes de bolsa, entre otros, y las fuentes expertas, de quienes se obtienen los análisis en profundidad.

\section{Macroeconomía}

Es la parte que estudia el comportamiento de los agentes económicos. Engloba los principales indicadores macroeconómicos, su evolución, las fuentes estadísticas, el sector exterior y la política económica del gobierno, entre otros.

Según explica Del Río (2004), la situación económica de un país se analiza examinando, en primer lugar, el nivel de producción, que establece el índice de empleo de los recursos productivos, incluyendo la masa laboral. Luego, el nivel de empleo y producción, junto a la evolución de los precios y los salarios, fija las rentas y su distribución. La evolución de las rentas y los precios, más la situación de la economía internacional, influyen en la demanda interna y externa.

La prensa económica peruana cubre los tres grandes sectores de la economía nacional: primario (agricultura, ganadería, pesca, etc.), secundario (industria y construcción) y terciario (comercio, transporte, turismo, etc.). Como fuentes oficiales en este campo, figuran, principalmente, los funcionarios del Ministerio de Economía, Ministerio de la Producción, Ministerio de Energía y Minas, Ministerio de Agricultura, Ministerio de Comercio Exterior y Turismo, Sunat, Sunarp, Indecopi, Dirección General de Medicamentos, Insumos y Drogas (Digemid).

Por el lado de las fuentes privadas, la información macroeconómica se recoge de los gremios empresariales, como la Sociedad Nacional de Industrias (SNI), la Asociación de Exportadores (Ádex), la Sociedad Nacio- 
nal de Pesquería (SNP), la Cámara Peruana de la Construcción (Capeco) y la Cámara de Comercio de Lima (CCL), entre otros.

Luego, la cobertura del empleo y evolución de la población activa se concreta con los informes del Instituto Nacional de Estadística e Informática (INEI); sin embargo, aunque los datos dan señas del síntoma del mercado laboral, la mirada es siempre incompleta, ya que no se mide el empleo informal, ampliamente extendido en el ámbito nacional. ${ }^{26}$

De manera similar, la información sobre la evolución de los salarios y los precios de venta de los sectores productivos en el Perú se recoge de las fuentes oficiales. Se comparan los resultados con los datos de periodos anteriores y se suelen incluir las opiniones de economistas miembros de empresas consultoras o del Instituto Peruano de Economía (IPE), que constituyen las fuentes expertas.

Montero (2013) explica la dificultad para acceder a las fuentes en el Perú:

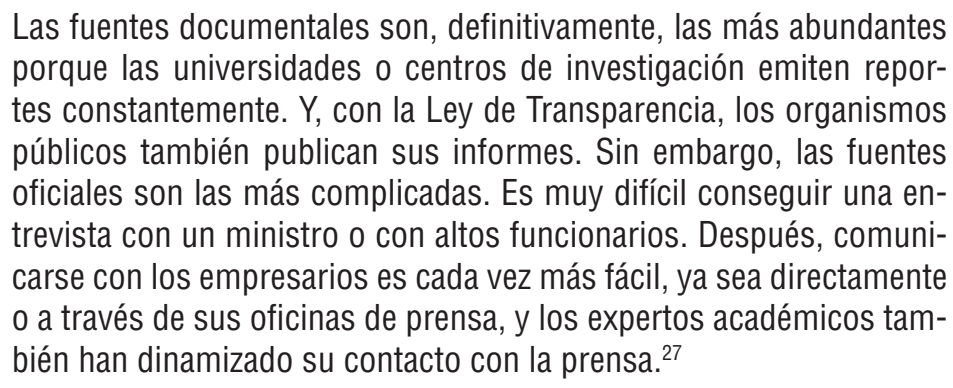

De este modo, la formación de los periodistas, analizada en el apartado anterior, así como su experiencia, serán las principales herramientas para hacer frente a la escasez de fuentes directas, ya que, para destacar lo relevante de los estudios y reportes publicados por centros de investigación o empresas consultoras, es indispensable conocer cómo funciona la economía del país y las consecuencias de las variaciones de cada indicador.

26 De acuerdo con la Organización Internacional del Trabajo (OIT), la población empleada (no agrícola) en el país asciende a 11,8 millones (la PEA total es de 15,5 millones, según el INEI). De esos 11,8 millones, el 68,6\% es informal, que equivale a 8,1 millones de trabajadores. Una de las tasas de informalidad laboral más altas de la región.

27 Montero Reyes, Ricardo (20 de octubre de 2013). Comunicación personal. 


\section{Microeconomía}

La información microeconómica es la información sobre las empresas. ${ }^{28}$ En el Perú, donde se ejerce una economía social de mercado, ${ }^{29}$ se desarrollan los dos tipos de empresas: públicas y privadas. Las públicas pertenecen al gobierno central, gobiernos regionales o municipios, y están presentes, principalmente, en los sectores eléctrico (actividades de generación y distribución), de infraestructura y transporte, hidrocarburos y remediación y actividades financieras. ${ }^{30}$

Las empresas privadas pertenecen a individuos particulares que pueden vender parte de su participación. La relación de los medios peruanos con estas fuentes institucionales sigue, en líneas generales, los referentes de la prensa internacional, interactuando así con los directivos de las empresas, los empleados y los sindicatos de trabajadores.

Cabe señalar que el mercado empresarial peruano está configurado de manera que unas pocas empresas tienen un liderazgo consolidado por encima de sus competidores, sobre todo en los sectores que llegan al consumidor final (alimentos y bebidas y servicios, entre otros). Esta situación genera una dependencia informativa por parte de las publicaciones hacia las fuentes, ${ }^{31}$ sobre todo si se parte de la premisa de que las noticias más importantes en el mundo de los negocios serán las que afecten al mayor número de personas posible.

Por esta razón, las organizaciones de los grupos económicos nacionales más grandes suelen generar portadas o artículos destacados. Los primeros diez grupos empresariales en el Perú se enumeran a continuación.

28 Se entiende por empresa una entidad formada por un capital que, aparte del propio trabajo de su promotor, puede contratar a trabajadores. Su propósito es lucrativo y su actividad puede ejercerse en el campo industrial, mercantil o en la prestación de servicios (Del Río, 2004).

29 El artículo 58 de la Constitución Política del Perú establece: "La iniciativa privada es libre. Se ejerce en una economía social de mercado. Bajo este régimen, el Estado orienta el desarrollo del país, y actúa principalmente en las áreas de promoción de empleo, salud, educación, seguridad, servicios públicos e infraestructura”.

30 En concreto, el último reporte del Ministerio de Economía (MEF) señala que a la fecha existen en el Perú 35 empresas estatales (incluyendo a EsSalud), de las que 34 se encuentran bajo el ámbito del Fondo Nacional de Financiamiento de la Actividad Empresarial del Estado (Fonafe), mientras que Petroperú está fuera de éste. La lista no toma en cuenta a las empresas de salud y saneamiento que pertenecen a los municipios y Gobiernos Regionales.

31 Para Endo (2006), esta aparente posición de poder de las fuentes empresariales suele decantar en uno de los problemas típicos que los periodistas económicos en todo el mundo buscan superar: ignorar los intereses no corporativos y seguir las agendas corporativas, generalmente enfocadas en sus resultados financieros. 


\section{Cuadro 4 \\ Ranking de holdings peruanos}

\begin{tabular}{|c|c|c|}
\hline Puesto $^{*}$ & Grupo & Ventas al 2011 $^{\text {** }}$ \\
\hline 1 & Romero & 8739,8 \\
\hline 3 & Buenaventura & 6241,5 \\
\hline 5 & Brescia & 4771,6 \\
\hline 8 & Intergroup & 3233,4 \\
\hline 12 & Gloria & 2497,3 \\
\hline 14 & Graña y Montero & 1810,8 \\
\hline 17 & Cillóniz & 1684,2 \\
\hline 19 & Pecsa & 1583,5 \\
\hline 20 & Hochschild & 1559,7 \\
\hline 23 & Ferreyros & 1298,7 \\
\hline
\end{tabular}

*Puesto que ocupan en la lista general de los mayores grupos que operan en el Perú.

**En millones de dólares. No incluye ingresos de subsidiarias fuera del país. Fuente: Perú Top Publications.

En general, las noticias empresariales que generan mayor interés tienen que ver con fusiones, asociaciones, compras, salidas a bolsa (oferta pública inicial, OPI), ofertas públicas de compra de acciones (OPA) u otros acuerdos interempresariales (Del Río, 2004). Y esta información se obtiene, en muchos casos, por los informes que emiten las empresas al regulador del mercado de valores, si las organizaciones cotizan en bolsa. En el ámbito nacional, la Superintendencia del Mercado de Valores (SMV) cumple esta función.

Asimismo, la información de negocios en el Perú también se encuentra presionada por los departamentos de relaciones públicas que se han arraigado en las empresas privadas, ya que necesitan de los periodistas económicos para comunicar su información corporativa a la sociedad.

Claramente, el país no vive un problema aislado, sino que la relación con los conocidos $P R$ constituye ya un problema típico de la prensa económica a nivel mundial. El buen manejo de estas interacciones y el uso periodístico de las fuentes depende de la experiencia y prudencia del periodista. Endo (2006, p. 63) apunta:

El crecimiento de los departamentos de Relaciones Públicas dentro de las instituciones es un problema, pues solo entregan el lado de la historia que es favorable a la compañía para la que trabajan. Nunca 
dicen si la empresa está despidiendo trabajadores o si está sufriendo problemas financieros. Para encontrar esa información, el periodista debe utilizar muchos contactos. Además, los relacionistas públicos ejercen un enorme poder a la hora de permitir y administrar las entrevistas que los periodistas tienen con los ejecutivos. ${ }^{32}$

Conviene apuntar que en el Perú -país conocido como una sociedad cuna de emprendedores $-{ }^{33}$ la información microeconómica en los medios generalistas suele dedicar un espacio a las historias de éxito de pequeños empresarios, incluyendo recomendaciones para los administradores de empresas que resultan interesantes para un público amplio.

\section{Finanzas}

El periodismo financiero hace eco de las actividades del sector financiero; es decir, de los bancos, las cajas de ahorro y las aseguradoras, además de las políticas monetarias del país.

En el Perú, la cobertura de esta subespecialización también se concentra en las ganancias y utilidades de las cajas, financieras y empresas de desarrollo para la pequeña y microempresa (Edypyme) y su nivel de morosidad, las tasas de interés de los créditos, las comisiones que cobran los bancos y el rendimiento de los instrumentos de inversión en el mercado financiero local, entre otros temas relacionados, así como las decisiones que toma el Banco Central de Reserva (BCR) sobre políticas monetarias ${ }^{34}$ y sus diferentes reportes sobre créditos y depósitos.

32 El autor cita, además, el testimonio de un periodista de la agencia Bloomberg, quien destaca el riesgo de la presión de los relacionistas públicos en los periodistas con menos experiencia: "Siempre es un peligro para los reporteros jóvenes terminar informando para las fuentes. Entonces, siempre les decimos 'tú escribes para 5,000 personas en el mundo; no para el relacionista público o para una compañía determinada’. Es difícil mantenerse al margen, dada la gran presión de las empresas".

33 El Global Entrepreneurship Monitor, en su última medición GEM 2012, señala que el Perú ocupa el tercer lugar de países intermedios en el índice Actividad Emprendedora en Etapa Temprana (TEA, por sus siglas en inglés). El TEA peruano es de 20\%, superado por Ecuador (27\%) y Chile (23\%). Según el Ministerio de la Producción, en el 2012 se crearon 177000 nuevas micro y pequeñas empresas (mypes) formales (con RUC activo), aunque la cifra también incluye formalizaciones nuevas filiales. Y, de acuerdo con el Colectivo Integral de Desarrollo (CID), cada año se concretan 130000 nuevos emprendimientos en el ámbito nacional.

34 El Banco Central de Reserva del Perú (BCRP) toma decisiones de política monetaria mediante el uso de un nivel de referencia para la tasa de interés del mercado interbancario. El Banco Central tiene autonomía dentro del marco de su Ley Orgánica y su finalidad es preservar la estabilidad monetaria. También se encarga de la emisión de billetes y monedas, y administra las reservas internacionales. Como un mandato dispuesto en el artículo 84 de la Constitución Política del Perú, la autoridad monetaria debe informar exacta y periódicamente al país sobre el estado de las finanzas nacionales. 
No obstante, la presencia de la información financiera en las secciones de economía de los medios nacionales de información general es menor en comparación con las noticias de macroeconomía o microeconomía, ya que tanto su elaboración como su lectura requieren de un mayor grado de especialización, que no tiene la mayor parte de periodistas económicos ni el público general. Además, la población peruana tiene un acceso limitado al sistema financiero, que reduce su interés por esta información. Según la Superintendencia de Banca, Seguros y AFP, el nivel de bancarización en el país apenas bordea el $30 \% .^{35}$

En este contexto, el Banco Central de Reserva es una de las principales fuentes oficiales y actor que condiciona esta subespecialidad. De igual forma, las entidades financieras, a través de sus fuertes departamentos de comunicación corporativa, interactúan constantemente con los periodistas, al igual que los gremios, como la Asociación de Bancos del Perú (Asbanc) o la Federación Peruana de Cajas Municipales de Ahorro y Crédito (Fepcmac).

Otro de los grandes temas del periodismo financiero es la información bursátil, que suele ocupar una subsección independiente en muchos medios internacionales. Ésta cubre las transacciones de compraventa de valores, tanto acciones como títulos de renta fija, donde se establecen las cotizaciones.

La prensa nacional mantiene su interés sobre el mercado de capitales, porque contribuye al desarrollo del país, en la medida que conforma una de las vías más eficientes a través de las cuales se canaliza la inversión. Sin embargo, al tratarse de un mercado incipiente, los indicadores bursátiles no resultan atractivos para gran parte de la población, a diferencia de los consumidores de las principales economías occidentales. ${ }^{36}$

35 De acuerdo con el Fondo Monetario Internacional (FMI) y la Federación Latinoamericana de Bancos (Felaban), la penetración bancaria del Perú se encuentra en el puesto 7 de la región, por debajo de las principales economías latinoamericanas. Asimismo, el acceso limitado de la población a los servicios financieros se evidencia con la penetración de los seguros a nivel nacional (monto de las primas entre el Producto Bruto Interno), que marca el 1,5\% del PBI, índice que se mantiene desde el año 2005.

36 La popularización de la información bursátil se consolidó en la mayoría de los países occidentales durante los últimos años del siglo XX con la maduración del 'capitalismo popular', donde millones de familias empezaron a participar en los mercados de valores (Vara, 2004). 
Montero (2013) anota que los medios peruanos de información general orientan sus noticias sobre el sistema financiero a temas utilitarios, de finanzas personales, para llegar al público masivo. Por ejemplo, se anotan artículos sobre cómo negociar un crédito hipotecario, el manejo de tarjetas de créditos, tasas de interés, etc. ${ }^{37}$

En general, desde las finanzas hasta el mundo empresarial, pasando por la macroeconomía, la calidad del acercamiento de los periodistas a los actores aquí expuestos y el tratamiento de la información dependerá de las posibilidades del reportero de analizar la realidad y plasmar su interpretación. Es decir que la función del periodista económico es la misma que la de sus colegas especializados en otras áreas ${ }^{38} \mathrm{y}$, por tanto, su objetivo es neutralizar los efectos de la situación asimétrica que comparte con las fuentes, para comunicar de forma clara, atractiva y con la intención de responder al derecho a la información de los ciudadanos.

\section{A modo de conclusión: los retos de la maduración}

$\mathrm{Al}$ establecer que la prensa económica peruana tiene un poco más de dos décadas de experiencia, se espera que el panorama próximo sea la etapa de maduración de la especialidad. Para esto, es indispensable, como ya se ha comentado a lo largo de este artículo, que el profesional asuma rol de periodista, en primer lugar, y su compromiso ante terceros de producir contenidos con tendencia a la verdad y ética de servicio.

Se concluye también de este análisis que el periodismo económico peruano, con sus características propias que se desprenden de la realidad nacional, se mueve entre fuentes de fácil acceso o gran disponibilidad (documentales) y otras escasas (fuentes privadas). La capacidad para llegar a ellas y obtener un reflejo certero de la vida económica del país depende de la formación de cada periodista.

37 Montero Reyes, Ricardo (20 de octubre de 2013). Comunicación personal.

38 Benito (1983, en: Esteve y Fernández, 1999, p. 219) anota claramente la relación entre los reporteros económicos y los objetivos del periodismo: "Los periodistas del mundo económico han de tener presente, en primer lugar, que su función no es aislada, que forma parte del marco general de las comunicaciones y que comporta, por tanto, los mismos riesgos de disfuncionalidad de todo profesional, con la responsabilidad añadida de pertenecer a una parcela de la realidad y de especialización no generalizable entre toda clase de públicos, en los que radicará siempre el éxito o el fracaso de la propia información". 
$\mathrm{Y}$, dado que los conocimientos sobre la ciencia económica tienen un nivel bajo entre los periodistas peruanos, la apuesta de las universidades y otras casas de estudio para formar a los profesionales que demanda la prensa económica jugará un papel fundamental en el desarrollo de la especialidad. Pues, sólo con una oferta de estudios adecuada, la formación de los periodistas en el Perú dejará de estar en manos de las organizaciones que también son fuentes y actores del mundo económico.

Con el frente de la educación completo, el periodismo económico en el Perú reforzará con todas las publicaciones el camino del análisis y la contextualización de la información. Una etapa madura de esta especialización periodística implica tomar en cuenta los aspectos más allá de la cifra. ${ }^{39}$

Por último como ha sucedido en el pasado, en la medida que siga creciendo la economía nacional, la demanda del público general por la información económica, financiera y empresarial seguirá en aumento. Se irá ampliando la cobertura de los temas y ningún medio de comunicación quedará ajeno a esta especialización, incluyendo la radio y la televisión. Y la educación, como motor de la simplicidad y el rigor, será el único camino para avanzar en la comprensión de los contenidos y su veracidad.

\section{Bibliografía}

América Economía (2012). "Las mejores universidades del Perú [versión electrónica]. Disponible en: http://rankings.americaeconomia. com/2012/las-mejores-universidades-de-peru/ranking.php [fecha de consulta: 11 de diciembre de 2012].

Arrese, A. (2000a). "Economía y medios de comunicación en la década de los setenta”. En: Comunicación y Sociedad, XIII (2), pp. 9-51.

39 Montero (2013) explica: "El futuro del periodismo económico en el país tiene que pasar por incluir más análisis y mucha más investigación. Porque, el contenido rápido, el dato puro se encuentra inmediatamente en Internet, como está pasando en las otras áreas del periodismo. Lo que se debe publicar es el contexto, las consecuencias. Por ejemplo, si el BCR eleva las tasas de referencia, no basta con indicar a cuánto subió, al día siguiente se tendrá que publicar una nota con profundidad". 
Arrese A. (2000b). "El desencuentro entre Periodismo y Economía”. En: Revista Empresa y Humanismo, 2, pp. 309-335.

Arrese, A. (2002a). Prensa económica: de la Lloyd's list al WSJ.com. Pamplona: Eunsa.

Arrese, A. (2004). “Información económica y de negocios”. En Fernández del Moral, J. (coord.). Periodismo especializado (pp. 285-315). España: Ariel.

Arrese, A. (2006). "Periodismo económico. Entre la simplificación y el rigor”. En: Cuadernos de Información, 19, pp. 42-49.

Bachmann, I. (2005). "Estudio en la prensa económica. La contaminación del discurso periodístico”. En: Cuadernos de Información, 18, pp. 122-131.

Borden, S. (2000). "A Model for Evaluating Journalist Resistance to Business Constraints". En: Journal of Mass Media Ethics, 15 (3), pp. 149-166.

Calvo, E. (2011). "La supervivencia del gran periodismo financiero”. Fonseca, Journal of Communication, 2, pp. 54-70.

Coca, C. y Díezhandino, M. (1997). Información económica: teoría y práctica. Barcelona: CIMS.

Endo, S. (2006). “The Business/Financial Journalism: The Role and the Ways to be Independent from the News Sources”. Disertación de MA en International Journalism, University of Leeds, 2006. Disponible en: http://pvac-webhost.leeds.ac.uk/ics/files/2012/05/ Shigeru_Endo.doc [fecha de consulta: 15 de octubre de 2013].

Esteve, F. y Fernández del Moral, J. (1999). Áreas de especialización periodística, Madrid: Editorial Fragua.

Lewin, G. S. (2002). “The Watchdog Role Business Reporting Need to Play”. En: Nieman Reports, verano, pp. 19-21. 
Loayza, N. (2008). "Causas y consecuencias de la informalidad en el Perú". En: Revista Estudios Económicos, 15, pp. 43-64.

Millman, G. (2006). "No longer just gray: Business Journalism takes off”. En: Financial Execute, octubre, pp. 18-23.

Real, E. (2007). "Formación y ejercicio profesional del periodista económico".En: XXII Congreso Internacional de Comunicación: Actas. Periodismo económico: viejos y nuevos desafíos (pp. 179-192). Pamplona: Universidad de Navarra.

Del Río, R. (2004). Periodismo económico y financiero. Madrid: Síntesis.

Stuller, J. (2008). “The Changing World of Business Journalism”. The Conference Board Review, julio/agosto, pp. 41-47.

Vara, A. (2004). "Naturaleza y retos actuales de la información económica". En: Sanz, C., Sotelo, J. y Rubio, A. (coords.). Prensa y periodismo especializado II (pp. 101-109). España: Editorial del Henares C. B..

Vara, A. y Arrese, A. (2003). "La formación del periodista económico". En: Profesionales para un futuro globalizado. Actas del XVII Congreso Internacional de Comunicación (pp. 493-509).Pamplona: Ediciones Eunate.

Watts, G. (2006). “Podría ser economía pero es periodismo". En: Initiative for Policy Dialogue, Columbia University. Disponible en: http:// policydialogue.org/files/publications/Writing_Tips_II.pdf [fecha de consulta: 23 de octubre de 2013].

Yamada, G. y Castro, J. (2010). La economía peruana en la última década: Mejor desempeño y mayor resiliencia a las crisis. Lima: Centro de Investigación de la Universidad del Pacífico. 